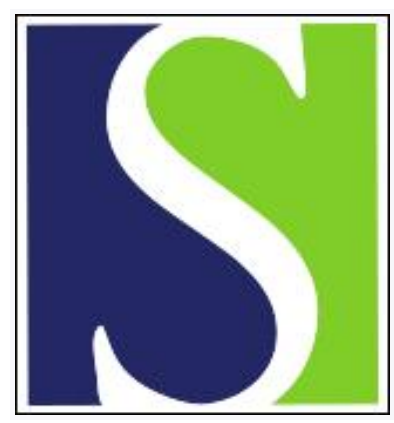

Scand J Work Environ Health 1998;24(5):407-413

https://doi.org/10.5271/sjweh.362

Issue date: Oct 1998

Year of birth and sperm count in 10 Danish occupational studies

by Bonde JPE, Kold Jensen T, Brixen Larsen S, Abell A, Scheike T, Hjollund NHI, Kolstad HA, Ernst E, Giwercman A, Skakkebæk NE, Keiding N, Olsen J

Key terms: birth cohort; Denmark; environment; epidemiology; male; occupational study; reproduction; secular trend; semen; sperm concentration; sperm count; sperm density; year of birth

This article in PubMed: www.ncbi.nlm.nih.gov/pubmed/9869313 


\title{
Year of birth and sperm count in 10 Danish occupational studies
}

\author{
by Jens Peter E Bonde, MD, ${ }^{1}$ Tina Kold Jensen, MD, ${ }^{2}$ Solveig Brixen Larsen, MD, ${ }^{1}$ Anette Abell, MD, ${ }^{1}$ \\ Thomas Scheike, PhD, ${ }^{3}$ Niels Henrik I Hjollund, MD, ${ }^{1}$ Henrik A Kolstad, MD, ${ }^{1}$ Erik Ernst, MD, ${ }^{4}$ Aleksander \\ Giwercman, MD, Niels E Skakkebæk, MD, ${ }^{2}$ Niels Keiding, PhD, ${ }^{3}$ Jørn Olsen, $M D^{5}$
}

\begin{abstract}
Bonde JPE, Kold Jensen T, Brixen Larsen S, Abell A, Scheike T, Hjollund NHI, Kolstad HA, Ernst E, Giwercman A, Skakkebæk NE, Keiding N, Olsen J. Year of birth and sperm count in 10 Danish occupational studies. Scand J Work Environ Health 1998:24(5):407-413.
\end{abstract}

\begin{abstract}
Objectives Several reports indicate a secular decline of human sperm counts. It is still not known if these findings are artifacts related to shortcomings in the data and applied methodologies. Even less is known about possible mechanisms, but it has been proposed that potential changes may be related to disruption of the hormonal regulation of testicular development in prenatal life. The objective of this study was to examine whether sperm count was related to year of birth.

Methods An analysis was made of the sperm count of 1196 men participating in 10 cross-sectional occupational sperm studies in 3 regions of Denmark from 1986 through 1995.

Results The median sperm concentration was 63 million per milliliter for men born in 1937-1949 and 52 million per milliliter for men born in 1970 or later, and the median total sperm was 206 million and 117 million, respectively. The inverse relationship between sperm concentration and year of birth was statistically significant even after adjustment for duration of sexual abstinence, season of the year, and study population. However, bias because of differential participation related to age and fertility or lack of comparability across the populations cannot be ruled out.

Conclusions The apparent decline of sperm count with increasing year of birth is compatible with the hypothesis of a common risk factor for male reproductive health operating in prenatal life or early childhood, but the evidence is circumstantial. Age-related selection bias is an alternative and perhaps not a less likely explanation.
\end{abstract}

Key terms birth cohort, environment, epidemiology, male reproduction, secular trend, semen, sperm concentration, sperm density.

Several reports indicate a decline of sperm count during the past several decades. Evidence is derived from studies of semen donors $(1-4)$ and men attending a medical examination because of infertility (5-11) and from an evaluation of published sperm densities in various groups $(12,13)$. A French study of 1351 sperm donor candidates and a Scottish study of 577 volunteer semen donors found an inverse relation between sperm concentration and year of birth $(2,3)$, but not all studies have shown this trend (14-16). It has been hypothesized that the sperm count for adult men may be adversely affected by hormonal disruption in prenatal life or early childhood (17). A low sperm count in adulthood can perhaps be viewed as a marker of impaired fetal testicular development. Accordingly, taking several assumptions into account, an examination of how the adult sperm count relates to year of birth provides information on the hypothesis that exposures in utero or in early childhood play a role in secular changes in sperm concentration.

We compiled data on sperm count and semen volume from 10 Danish occupational studies comprising 1196 men. Our objective was to identify the relation between adult sperm count and year of birth. The study populations were not selected by fertility-related criteria, as in

1 Department of Occupational Medicine, Aarhus University Hospital, Århus, Denmark.

2 Department of Growth and Reproduction, The National Hospital, Copenhagen, Denmark.

3 Department of biostatistics, University of Copenhagen, Copenhagen, Denmark.

4 Reproductive Toxicology Unit, Institute of Anatomy, University of Aarhus, Århus, Denmark.

5 The Danish Epidemiology Science Center, University of Aarhus, Århus, Denmark.

Reprint requests to: Dr Jens Peter Bonde, Department of Occupational Medicine, The Steno Center, Aarhus University Hospital, Nørrebrogade 44, DK - 8000 Århus C, Denmark. [E-mail: J.P.Bonde@usa.net] 
earlier studies of semen donors and infertility clients, and the approach allows control for important determinants of sperm count, such as duration of sexual abstinence, season, and laboratory methods.

\section{Populations and methods}

\section{Study populations}

We used the data from 10 separate Danish occupational cross-sectional sperm studies conducted from 1986 through 1995 at 3 centers (18-26) (table 1). Most of the studies were designed to examine adverse effects of workplace exposures such as metal welding (study 1, 4, 10 ), pesticides (study $2,5,6$ ), styrene (study 7 ), organic solvents (study 9), and psychological distress (study 1) on male reproductive function. However, 2 of the studies were undertaken to create a reference population of manual workers (study 3) and organic farmers (study 8). Eligible men were invited to participate by written brochures, and, if feasible, the men received information at workplace meetings. Within each study, men of different ages were approached the very same way. The results of the individual semen analysis were provided on request after completion of the data collection, but an individual infertility examination and counseling were not offered as part of the studies. The eligibility criteria differed only slightly between the studies (age 18-20 to $45-60$ years, no vasectomy) with the exception of study 1 , which included only cohabiting men aged 20 37 years. The exceptional study only enrolled couples without reproductive experience who discontinued birth control to get a child. The lowest rate of participation was some $10-20 \%$ and the highest was $90 \%$ (table 1). In most of the studies the men provided several semen samples, but only the first samples were used in the pooled analysis.

\section{Semen analysis}

In all the studies the men were asked to collect semen by masturbation. With few exceptions samples were collected at home but examined in the laboratory within 2 hours. The duration of sexual abstinence and spillage was recorded. The semen volume was measured in a graded tube with $0.1-\mathrm{ml}$ accuracy. Formalin-fixed sperm cells were counted in either a Makler or Neubauer chamber (Aarhus) or a Bürger-Türk chamber (Aalborg and Copenhagen) using the phase-contrast technique at a magnification of $200 \times$. An appropriate formalin dilution was found after a preliminary examination of the undiluted sample - most often 1:100. The total sperm count was computed by multiplying the sperm concentration by the semen volume. All the analyses were carried out by trained laboratory technicians in accordance with guidelines of the World Health Organization (27). The interlaboratory variation in sperm count was evaluated by

Table 1. Characteristics of the 10 occupational studies used in the analysis.

\begin{tabular}{|c|c|c|c|c|c|c|c|c|c|c|c|}
\hline \multirow[t]{2}{*}{ Population } & \multirow[t]{2}{*}{$\begin{array}{l}\text { Sampling } \\
\text { year }\end{array}$} & \multirow[t]{2}{*}{ Center } & \multirow[t]{2}{*}{$N$} & \multirow[t]{2}{*}{$\begin{array}{l}\text { Participation } \\
\text { rate (\%) }\end{array}$} & \multicolumn{2}{|c|}{$\begin{array}{l}\text { Age (years) } \\
\text { at sampling }\end{array}$} & \multicolumn{2}{|c|}{ Bitth year } & \multicolumn{2}{|c|}{$\begin{array}{l}\text { Median sperm } \\
\text { density }\end{array}$} & \multirow[t]{2}{*}{ Reference } \\
\hline & & & & & Median & Range & Median & Range & Million/m/ & $\begin{array}{c}25-75 \\
\text { percentiles }\end{array}$ & \\
\hline $\begin{array}{l}1 \text { Metal workers } \\
\text { and husbands } \\
\text { to clerks and } \\
\text { nurses }\end{array}$ & $1992-1995$ & $\begin{array}{l}\text { Aarhus/ } \\
\text { Copenhagen }\end{array}$ & 410 & $10-20$ & 28.0 & $21-37$ & 1966 & $1956-1974$ & 50.0 & $25-88$ & Bonde et al, 1998 (18) \\
\hline 2 Farmers & $1995-1996$ & Aarhus & 250 & 32 & 37.8 & $26-56$ & 1958 & $1945-1970$ & 58.5 & $31-102$ & $\begin{array}{l}\text { Larsen et al, in press } \\
(19)\end{array}$ \\
\hline $\begin{array}{l}3 \text { Repairmen } \\
\text { and clerks }\end{array}$ & $1989-1990$ & Copenhagen & 135 & 18 & 33.0 & $21-44$ & 1957 & $1944-1967$ & 48.0 & $24--97$ & $\begin{array}{l}\text { Jensen et al, } 1996 \\
(20)\end{array}$ \\
\hline 4 Metal workers & 1987 & Aalborg & 131 & 37 & 31.0 & $20-50$ & 1956 & $1937-1961$ & 51.5 & $41-72$ & Bonde, $1990(21)$ \\
\hline $\begin{array}{l}5 \text { Greenhouse } \\
\text { workers }\end{array}$ & 1994 & Aarhus & 121 & 64 & 27.0 & $20-43$ & 1966 & $1950-1974$ & 80.0 & $36-142$ & Abel et al, 1997 (22) \\
\hline $\begin{array}{l}6 \text { Members of } \\
\text { organic food } \\
\text { consumers } \\
\text { organization }\end{array}$ & $1993-1995$ & Copenhagen & 53 & . & 34.0 & $25-43$ & 1959 & $1949-1967$ & 69.0 & $30-138$ & $\begin{array}{l}\text { Jensen et al, } 1996 \\
(20)\end{array}$ \\
\hline $\begin{array}{l}7 \text { Reinforced } \\
\text { plastics } \\
\text { workers }\end{array}$ & $1994-1995$ & Aarhus & 31 & 32 & 27.0 & $20-46$ & 1968 & $1949-1974$ & 54.0 & $12-92$ & $\begin{array}{l}\text { Spano et al, in } \\
\text { press (23) }\end{array}$ \\
\hline $\begin{array}{c}8 \text { Members of } \\
\text { organic farmers } \\
\text { organization }\end{array}$ & 1994 & Aarhus & 30 & 70 & 35.5 & $28-44$ & 1958 & $1950-1965$ & 100.0 & $50-168$ & Abell et al, 1994 (24) \\
\hline 9 Flexo printers & 1984 & Aalborg & 19 & 90 & 33.0 & $23-45$ & 1951 & $1939-1961$ & 55.0 & $46-89$ & Bonde et al, 1987 (25) \\
\hline 10 Metal workers & 1989 & Aalborg & 16 & 85 & 33.0 & $23-49$ & 1955 & $1940-1965$ & 51.0 & $32-79$ & Bonde, 1992 (26) \\
\hline
\end{tabular}


comparing the counting (28 samples) of a laboratory technician from 2 of the centers (Aarhus and Copenhagen). No systematic difference was found (paired T-test: $\mathrm{T}=0.23, \mathrm{P}=0.82$ ).

\section{Data analysis}

The relation between the semen variables (sperm concentration, semen volume, total sperm count) and year of birth was analyzed by linear regression for each of the 10 populations. The models also included duration of sexual abstinence (days) and the season when the sample was provided (October-March: yes;no). The potential effect of age was taken into account by including only men between 20 and 50 years of age (on the assumption that biological age has no impact on sperm concentration in the fertile age range - see the discussion), while calendar time was accounted for by stratification according to study group. Appropriate transformations of several variables were necessary to obtain normality and an equality of variance. Cube root transformation was used for the sperm concentration, seminal volume, and total sperm count. The period of abstinence was transformed by the natural logarithm to adjust for the nonlinear relationship between the abstinence period and the sperm concentration. In order to present interpretable regression coefficients, we also used base e logarithmic transformation of the dependent variables if the statistical significance was not dependent on type of transformation. In a subsequent step, data from all the study groups were pooled into 1 model that also included the study group (dummy variables). Furthermore, interaction between population and year of birth and abstinence period was examined to evaluate a possible different effect of these variables in the 10 populations. The main effects remained in the models whatever the strength of association or level of significance, but the interaction terms were excluded if the P-value was higher than $20 \%$. Whenever a relevant variable was missing, the observation was excluded from the study. The fit of the regression models was evaluated by testing the residuals for normality and by inspecting the residual plots. (See the results section.) The SAS statistical package was used to compute the regressions (28).

\section{Results}

The crude relations between the sperm concentrations and the year of birth in each of the populations including more than 100 men are outlined in figure 1. After adjustment for the effects of season and the duration of abstinence, the inverse associations between sperm concentration and year of birth were statistically significant at the $5 \%$ level in 2 of the studies (studies 2 and 3 ) and negative but not significant in 4 other studies (studies 1 , 4,7 , and 9). Similar results were obtained for total sperm count, while the adjusted regression coefficients of semen volume for year of birth were positive in 6 studies and negative in 4 studies.

The distributions of the semen variables in relation to the year of birth in the pooled data are shown in table 2 and figure 1 . The sperm concentration and total sperm count were low for men born late in the study period, while the median semen volume was rather constant throughout all the years of birth. The median sperm concentration was 63 million/milliliter for the men born in 1937-1949 and 52 million/milliliter for the men born in 1970 or later, and the median total sperm count was 206 million and 117 million, respectively (table 2 ). The inverse relationship between sperm concentration, total sperm count, and year of birth was statistically significant at the 5\% significance level even after adjustment for population, duration of abstinence, and season (table 3 ). The interaction terms did not contribute to the regression models and were excluded. Plots of residuals versus year of birth indicated a random scattering, and the distribution of the residuals did not deviate significantly from normality (Kolgomorov test: cube root of the concentration: $\mathrm{w}=0.989, \mathrm{P}=0.06$; cube root of the total count: $\mathrm{w}=0.989, \mathrm{P}=0.90)$.

The considerable heterogeneity of the sperm concentration and total count was attributable to 3 of the 10 studies (study 5, 6, and 8) (table 1). A separate regression analysis omitting these 3 studies revealed essentially the same results. When population, duration of abstinence, and season were taken into account, the sperm concentration was $1.24 \%$ lower per year $(95 \%$ CI $0.40-2.08$, $\mathrm{P}<0.005$ ), and the total sperm count was $1.20 \%$ lower per year $(95 \% \mathrm{CI} 0.12-2.28, \mathrm{P}<0.05)$. The results were not dependent on the type of transformation or whether or not nonsignificant covariates were retained in the model.

\section{Discussion}

The sperm concentration and the total sperm count of 1196 Danish men from 10 different populations declined significantly with increasing year of birth from 1937 to 1974, while semen volume remained constant. Although men born in the first part of the period had a longer average duration of abstinence time, the findings were apparently not attributable to this factor, nor to the possible effect of season during which the sample was provided. The 10 studies were performed at 3 different laboratories, but the same direction of association was observed at all the sites and all the comparisons were done within the same study sample. 

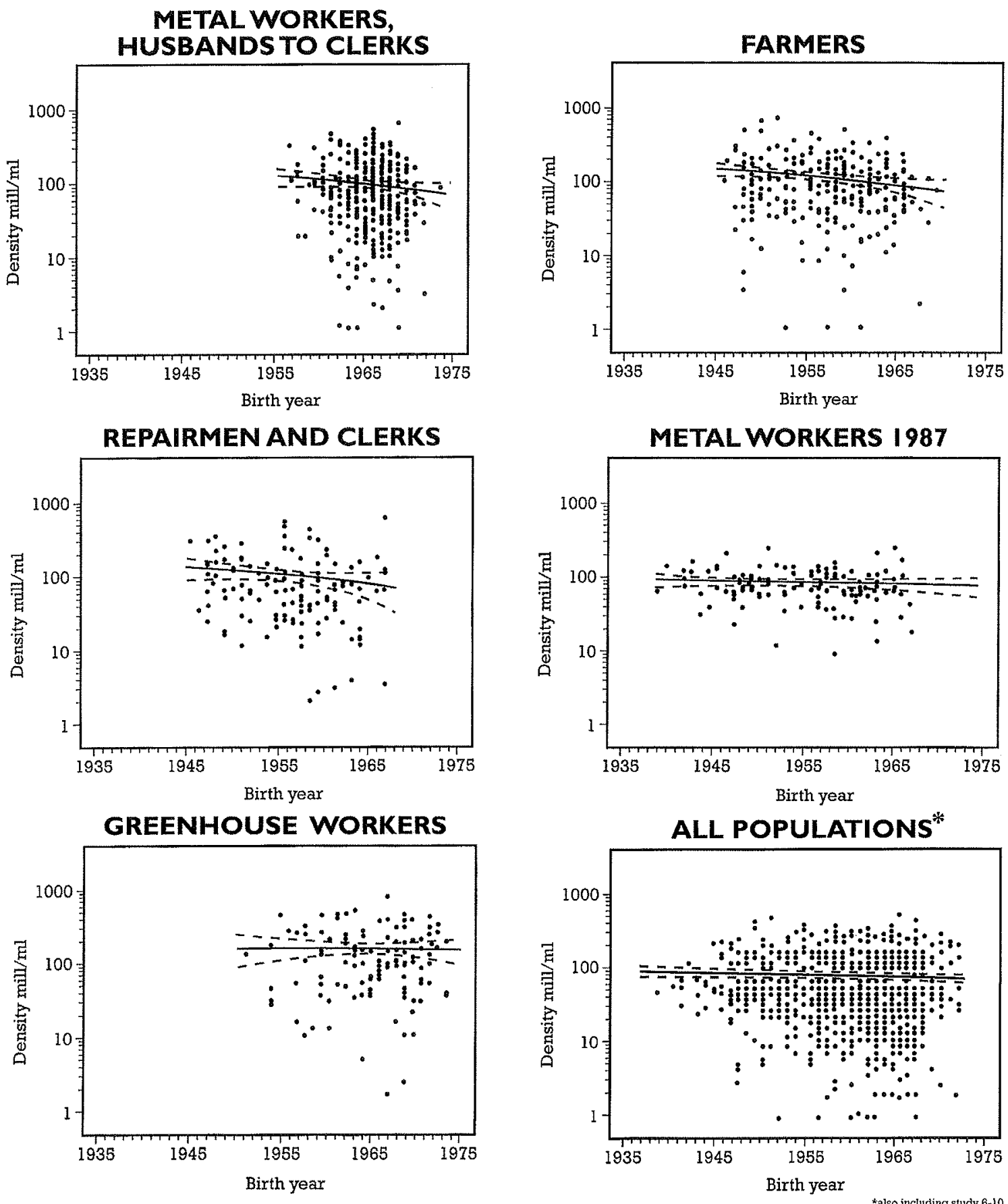

Figure 1. Relationship between sperm concentration and year of birth in 10 occupational populations - linear regression with $95 \%$ confidence interval.

These findings are compatible with a detrimental prenatal exposure whose prevalence has increased over time, but this interpretation rests upon several strong assumptions.

First, it was assumed that postnatal exposure to testicular toxicants remained unchanged over time. Most of the study groups were identified by workplace exposures, and bias would have been introduced if a deleterious occupational exposure had been related to year of birth.
Among the oldest men, about 50\% were exposed to some suspected occupational exposure, whereas fewer from the later cohorts were exposed. If exposure is related to semen quality, the relationship would have tended to underestimate the birth cohort effect that we found. However, other types of exposures in childhood or adult life might operate in the opposite direction $(29,30)$.

Second, it was assumed that there is no age impact on sperm count before the age of 50 years. It was not 
Table 2. Distribution of semen variables and potential confounding factors in relation to year of birth.

\begin{tabular}{|c|c|c|c|c|c|c|c|c|c|c|c|c|c|c|}
\hline \multirow[t]{2}{*}{$\begin{array}{l}\text { Year of } \\
\text { birth }\end{array}$} & \multirow[t]{2}{*}{ N } & \multirow[t]{2}{*}{$\begin{array}{c}\text { Participa- } \\
\text { tion ratea } \\
(\%)\end{array}$} & \multicolumn{2}{|c|}{$\begin{array}{l}\text { Days of } \\
\text { abstinence }\end{array}$} & \multicolumn{2}{|c|}{$\begin{array}{c}\text { Age at } \\
\text { sampling }\end{array}$} & \multirow{2}{*}{$\begin{array}{c}\text { Proportion } \\
\text { provided } \\
\text { October to } \\
\text { March } \\
(\%)\end{array}$} & \multirow{2}{*}{$\begin{array}{c}\text { Proportion } \\
\text { of analyses } \\
\text { in Aarhus/ } \\
\text { Copenhagen/ } \\
\text { Aalborg }\end{array}$} & \multicolumn{2}{|c|}{$\begin{array}{c}\text { Sperm } \\
\text { concentration } \\
\text { (million } / \mathrm{ml})\end{array}$} & \multicolumn{2}{|c|}{$\begin{array}{l}\text { Total sperm } \\
\text { count (million) }\end{array}$} & \multicolumn{2}{|c|}{$\begin{array}{c}\text { Semen } \\
\text { volume }(\mathrm{ml})\end{array}$} \\
\hline & & & Mean & SD & Mean & $\mathrm{SD}$ & & & Median & n $\begin{array}{c}25-75 \\
\text { percentiles }\end{array}$ & Median & $\begin{array}{c}25-75 \\
\text { percentiles }\end{array}$ & Median & $\begin{array}{c}25-75 \\
\text { percentiles }\end{array}$ \\
\hline $1935-1949$ & 123 & 30.9 & 4.15 & 2.10 & 44.0 & 3.58 & 50.4 & $33 / 23 / 44$ & 63.0 & $42.0-97.5$ & 205.8 & $119.0-345.0$ & 3.0 & $2.0-4.6$ \\
\hline $1950-1959$ & 342 & 38.6 & 3.95 & 2.74 & 36.5 & 4.39 & 52.3 & $51 / 30 / 19$ & 62.5 & $31.0-100.0$ & 185.0 & $93.6-330.0$ & 3.0 & $2.1-4.3$ \\
\hline $1960-1969$ & 660 & 43.2 & 3.92 & 3.24 & 28.6 & 3.21 & 66.8 & $59 / 35 / 6$ & 54.0 & $28.0-91.5$ & 148.2 & $72.0-279.8$ & 3.0 & $2.0-4.0$ \\
\hline $1970-1975$ & 71 & 61.9 & 3.51 & 3.54 & 22.8 & 1.54 & 81.7 & $75 / 25 / 0$ & 52.0 & $27.0-106.0$ & 117.0 & $67.2-248.4$ & 2.6 & $1.8-3.7$ \\
\hline
\end{tabular}

a Data on age in the source populations were only available in studies $2,3-4$, and $7-10(50 \%$ of the cohort).

Table 3. Regression coefficients ${ }^{a}$ for sperm density, semen volume, and total sperm count according to year of birth, duration of sexual abstinence, season, and study group (multiple linear regression on pooled data).

\begin{tabular}{|c|c|c|c|c|c|c|}
\hline & \multicolumn{2}{|c|}{ Logarithm of sperm density (mill/ml) } & \multicolumn{2}{|c|}{ Logarithm of semen volume $(\mathrm{ml})$} & \multicolumn{2}{|c|}{ Logarithm of total sperm count (millions) } \\
\hline & Regression coefficient & $95 \% \mathrm{Cl}$ & Regression coefficient & it $95 \% \mathrm{Cl}$ & Regression coefficient & $95 \% \mathrm{Cl}$ \\
\hline Year of birth (years) & -0.88 per year & -0.10 to -1.66 & 0.09 per year & -0.48 to 0.66 & -1.07 per year & -0.07 to -2.07 \\
\hline Abstinence (day 1 to day 7 ) & 8.10 per day & 5.96 to 10.24 & 6.10 per day & 4.55 to 7.64 & 14.50 per day & 11.80 to 17.20 \\
\hline Season (October-March) & 4.75 in winter & -5.24 to 14.75 & 9.87 in winter & 2.58 to 17.16 & 2.50 in winter & -10.20 to 15.16 \\
\hline
\end{tabular}

a The regression coefficients indicate the percentage of change in the response variables when the independent variable changed from one level to another. For example sperm density declined by $0.88 \%$ for each year of advancing birth year.

possible in this study to separate a birth cohort effect from an age effect. Several cross-sectional studies of fertile men have not found any age-related deterioration of sperm concentration between 20 and 59 years of age, a finding which contradicts our results $(31,32)$, and even high age ( $60-88$ years) may not be associated with reduced semen quality (32). Such studies are biased, however, if elder men with high reproductive performance are more likely to provide a semen sample. An autopsy study of 130 men with sudden unattended death reported $30 \%$ higher daily sperm production in the younger men $(\mathrm{N}=89,21-50$ years $)$ than in the older men $(\mathrm{N}=43$, $51-80$ years), but the effect of age observed in that study apparently started after 50 years of age (33). If age is related to sperm concentration because of a longer duration of sexual abstinence in older age, this effect was adjusted for in this study. In any case, since age reflects cumulative exposure and age-related biological changes, the effect of age is expected to operate in the opposite direction, as found in this study, and therefore the shortcoming of cross-sectional sampling does not explain the results.

Third, it was assumed that selection into the studies was of the same magnitude in the different birth cohorts or was unrelated to sperm concentration. The participation rate was low in most studies (table 1), and the semen samples probably do not truly reflect the source populations. An earlier study indicated that subfertile men are more motivated to participate in occupational sperm studies (34). Moreover, the proportion of men who provided a semen sample declined with age in the 7 studies including data on the age of nonparticipating men (table 2). Subfertile young men are perhaps more likely to participate than older subfertile men because they might be more interested in knowing their sperm count. We were able to examine possible preferential participation related to age and subfertility in 2 studies in which selfreported data on subfertility among both the participating and nonparticipating men were available (study 2 and 4) (table 1). In these studies the men were asked if they had ever tried to initiate a pregnancy for at least 6 months (study 2) or 2 years (study 4) without success. The proportion of men providing semen samples was higher among the men with self-reported subfertility (OR 1.8, $95 \%$ CI $1.3-2.6)$ and among the men under 40 years of age (OR 1.7, 95\% CI 1.3-2.1), but no significant interaction between age and reduced fecundity with respect to semen donation was found (OR $1.2,95 \% \mathrm{Cr} 0.61-$ 2.46) (34). Among farmers (study 2), the proportion of men reporting infertility was $7 \%, 25 \%$, and $16 \%$ in the age groups $20-30,31-40$, and $41-50$ years $(P>0.05)$, respectively. Among metal workers (study 4), the corresponding frequencies of infertility were $13 \%, 21 \%$, and $18 \%(\mathrm{P}<0.05)$. Although these data do not indicate a strong preferential participation of young subfertile men, it cannot be ruled out that men with reduced fertility were more interested in providing a semen sample if they were of child-bearing age than if they were not. This type of 
selection bias may indeed explain the higher sperm concentration observed among the men born before the 1950s.

Finally, the underlying birth cohorts must be comparable at base-line (birth), which may be a critical issue for occupational populations that vary in size and recruitment over time. A smaller fraction of the youngest birth cohorts than the older cohorts became manual workers. Furthermore, confounding factors must be adequately controlled for, and, since they are only partly known, the findings may be explained by confounding. The duration of sexual abstinence is strongly related to sperm concentration and semen volume. The sperm concentration increases by $5-15 \%$ per day of sexual abstinence during the first 7 days, but longer abstinence is not associated with additional increment of sperm output (35). The abstinence period was expectedly longer among the oldest men from the earliest birth cohorts (table 2), but similar results were obtained in regression models whether crude abstinence values from 1 to 7 days or the logarithm to the abstinence was included. Semen quality has been reported to be higher during winter than summer (36), and a higher percentage of men born between 1935 and 1959 provided semen samples during summer, and more men born between 1960 and 1975 collected semen samples during the winter (October to March). Adjustment for season had, however, only a marginal impact on the findings of sperm concentration in relation to birth year.

Several reports on time trends of sperm counts from recent years suffer from methodological shortcomings. A Danish study of infertility clients indicated a decline of sperm concentration in adult men from 1952 to 1972 (7). The findings of this early report are not consistent with the results of a more recent study from 4 Danish infertility clinics showing a decline in sperm concentration among men born in 1950 and subsequent years but not among men born in 1925-1950 (11), as would be expected from the Bostofte study (7). These and other studies of infertility clients $(5,6,8-10)$ may be biased if time-dependent changes in help seeking for infertility treatment is related to semen quality, and we know that more infertile couples seek help now than 10 years ago (37). Likewise, time trend studies based on semen donors (2-4) are biased if the recruitment of donor candidates and shifting response rates are related to male fecundity. Therefore, potential selection bias is a serious problem that is difficult to address with respect to other studies published so far because the source populations were ill defined and the response rates are impossible to compute.

In conclusion, the observed decline in sperm concentration and total sperm count with increasing year of birth among men born from 1937 through 1974 is compatible with the hypothesis that semen quality has declined in Denmark during the post war period and that this potential secular change is caused by factors operating in prenatal life or early childhood. However, bias due to differential participation related to age and fertility or lack of comparability across the study populations are alternative and perhaps not less likely explanations. It is still not clear whether semen quality in the general population has undergone any secular change at all.

\section{Acknowledgments}

The study was supported by a grant from the Aarhus University Research Foundation (J 1994-7430-1).

\section{References}

1. Leto S, Frensilli FJ. Changing parameters of donor semen. Fertil Steril 1981;36:766-70.

2. Auger J, Kunstman JM, Czyglik F, Jouannet P. Significant decrease of semen characteristics of fertile men from Paris area during the last 20 years. N Engl J Med 1995;332:281—5.

3. Irvine $\mathrm{S}$, Cawood $\mathrm{E}$, Richardson D, MacDonald E, Aitken J. Evidence of deteriorating semen quality in the United Kingdom: birth cohort study in 577 men in Scotland over 11 years. BMJ 1996;312:467-71.

4. Van Waeleghem K, De Clereq N, Vermeulen L, Schoonjans $\mathrm{F}$, Comhaire F. Deterioration of sperm quality in young healthy Belgian men. Hum Reprod 1996;11:325-9.

5. Macleod J, Wang Y. Male fertility potential in terms of semen quality: a review of the past, a study of the present. Fertil Steril 1979:31:103-16.

6. Bendvold E. Semen quality in Norwegian men over a 20-year period. Int J Fertil 1989;34:401-4.

7. Bostofte E, Serup J, Rebbe H. Has the fertility of Danish men declined through the years in terms of semen quality? A comparison of semen qualities between 1952 and 1972. Int J Fertil 1983;28:91-5.

8. Osser S, Liedholm P, Ranstam J. Depressed semen quality: a study over two decades. Arch Androl 1984;12:113 -6.

9. Vierula M, Niemi M, Keiski A, Saaranen M, Saarikoski S, Suominen J. High and unchanged sperm counts of Finnish men. Int J Androl 1996;19:11-7.

10. Adamopoulos DA, Pappa A, Nicopoulou S, Andreou E, Karamertzamis M, Michopoulos J, et al. Seminal volume and total sperm number trends in men attending subfertility clinics in the greater Athens area during the period 1977-1993. Hum Reprod 1996;11:1936-41.

11. Zheng Y, Bonde JP, Ernst E, Mortensen JT, Egense J. Is semen quality related to the year of birth among Danish infertility clients? Int J Epidemiol 1997;26:1289-97.

12. James WH. Secular trend in reported sperm counts. Andrologia $1980 ; 12: 381-8$.

13. Carlsen E, Giwercmann A, Keiding N, Skakkebæk NE. Evidence for decreasing quality of semen during past 50 years. BMJ 1992;305:609-13.

14. Bujan L, Mansat A, Pontonnier F, Mieusset R. Time series analysis of sperm concentration in fertile men in Toulouse, France between 1977 and 1992. BMJ 1996;312:471-2. 
15. Fisch H, Feldshuh J, Goluboff ET, Broder SJ, Barad DH. Semen analyses in 1,283 men from the United States over a 25-year period: no decline in quality. Fertil Steril 1996;65:1009-14.

16. Paulsen CA, Berman NG, Wang C. Data from men in greater Seattle area reveals no downward trend in semen quality: further evidence that deterioration of semen quality is not geographically uniform. Fertil Steril 1996;65:1015-20.

17. Sharpe RM, Skakkebæk NE. Are oestrogens involved in falling sperm counts and disorders of the male reproductive tract? Lancet 1993;341:1392-5.

18. Bonde JPE, Hjollund NHI, Jensen TK, Ernst E, Kolstad H, Henriksen TB, et al. A follow-up study of environmental and biological determinants of fertility among 430 Danish first pregnancy planners: design and methods. Reprod Toxicol 1998; 12:19-27.

19. Larsen SB, Giwercman A, Spano M, Bonde J, Asclepios. A longitudinal study of semen quality in pesticide spraying Danish farmers. Reprod Toxicol. In press.

20. Jensen TK, Giwercman A, Carlsen E, Scheike T, Skakkebæk NE. Semen quality among members of organic food associations in Zealand, Denmark [letter]. Lancet 1996;347:1844.

21. Bonde J. Semen quality and sex hormones among mild steel and stainless steel welders: a cross sectional study. $\mathrm{Br} J$ Ind Med 1990;47:508-14.

22. Abel A, Ernst E, Bonde J. Semen quality and sex hormones among green house workers [abstract]. In: Aarhus University Hospital. International symposium on environment, lifestyle and fertility, Aarhus Dec 7-10 1997. Aarhus (Denmark): Aarhus University Hospital, 1997.

23. Spano M, Kolstad H, Larsen S, Cordelli E, Letter G, Giwercman $A$, et al. The applicability of the flow cytometric sperm chromatin structure assay in epidemiological studies. Hum Reprod. In press.

24. Abell A, Ernst E, Bonde J. High sperm density among members of organic farmers' association [letter]. Lancet 1994;343:149.

25. Bonde J, Mortensen JT, Johansen JP. Toksisk encefalopati og sædkvalitet blandt ansatte i en flexotrykvirksomhed. [Organic brain damage and semen quality in flexo printers]. Ugeskr Lag 1987;149:469-471. English summary.

26. Bonde J. Semen quality in welders exposed to radiant heat. $\mathrm{Br}$ J Ind Med 1992;49:5-10.

27. Belsey MA. WHO laboratory manual for the examination of human semen and semen-cervical muscus interaction. Singapore: World Health Organization (WHO), Press Concern, 1980.

28. SAS Institute Inc. SAS/STAT user's guide, version 6. 4th ed. Cary (NC): SAS Institute, 1990:1071-126.

29. Vine MF, Margolin BH, Morrison HI, Hulka BS. Cigarette smoking and sperm density: a meta-analysis. Fertil Steril 1994;61:35-43.

30. Bonde J, Giwercman A. Occupational hazards to male fecundity. Reprod Med Rev 1995;4:59—73.

31. Schwartz D, Mayaux MJ, Spira A, Moscato ML, Jouannet P, Czyglik F, et al. Semen characteristics as a function of age in 833 fertile men. Fertil Steril 1983;39(4):530-5.

32. Nieschlag E, Lammers U, Freischem CW, Langer K, Wickings EJ. Reproductive functions in young fathers and grandfathers. J Clin Endocrinol Metab 1982;55:676-81.

33. Johnson L, Petty CS, Neaves WB. Influence of age on sperm production and testicular weights in men. J Reprod Fert $1984 ; 70: 211-8$.

34. Larsen SB, Abell A, Bonde JPE. Selection bias in occupational sperm studies. Am J Epidemiol 1998;147:681-5.

35. Schwartz D, Laplanche A, Jouannet P, David G. Withinsubject variability of human semen in regard to sperm count, volume and number of spermatozoa and length of abstinence. J Reprod Fertil 1979;57:391—5.

36. Levine RJ, Bordson BL, Mathew RM, Brown MH, Stanley JM, Starr TB. Deterioration of semen quality during summer in New Orleans. Fertil Steril 1988;49:900-7.

37. Olsen J, Kuppers-Chinnow M, Spinelli A. Seeking medical help for subfecundity: a study based upon surveys in five European Countries. Fertil Steril 1996;66:95-100.

Received for publication: 12 September 1997 